Toll signals regulate dorsal-ventral patterning and anterior-posterior placement of the embryo in the hemipteran Rhodnius prolixus

Berni et al. 


\title{
Toll signals regulate dorsal-ventral patterning and anterior-posterior placement of the embryo in the hemipteran Rhodnius prolixus
}

\author{
Mateus Berni 1,2,3, Marcio Ribeiro Fontenele ${ }^{1,2}$, Vitoria Tobias-Santos ${ }^{2,4}$, Aline Caceres-Rodrigues ${ }^{2,4}$, \\ Flavia Borges Mury ${ }^{2,4}$, Raquel Vionette-do-Amaral ${ }^{2,5}$, Hatisaburo Masuda ${ }^{2,5}$, Marcos Sorgine ${ }^{2,5}$, \\ Rodrigo Nunes da Fonseca ${ }^{2,4^{*}}$ and Helena Araujo ${ }^{1,2^{*}}$
}

\begin{abstract}
Background: Insect embryonic dorso-ventral patterning depends greatly on two pathways: the Toll pathway and the Bone Morphogenetic Protein pathway. While the relative contribution of each pathway has been investigated in holometabolous insects, their role has not been explored in insects with a hemimetabolous type of development. The hemimetabolous insect Rhodnius prolixus, an important vector of Chagas disease in the Americas, develops from an intermediate germ band and displays complex movements during katatrepsis that are not observed in other orders. However, little is known about the molecular events that regulate its embryogenesis. Here we investigate the expression and function of genes potentially involved in the initial patterning events that establish the embryonic dorso-ventral axis in this hemipteran.

Results: We establish a staging system for early embryogenesis that allows us to correlate embryo morphology with gene expression profiles. Using this system, we investigate the role of Toll pathway genes during embryogenesis. Detailed analyses of gene expression throughout development, coupled with functional analyses using parental RNA interference, revealed that maternal Toll is required to establish germ layers along the dorso-ventral axis and for embryo placement along the anterior-posterior axis. Interestingly, knockdown of the Toll pathway effector Rp-dorsal appears to regulate the expression of the Bone Morphogenetic Protein antagonist Rp-short-gastrulation.
\end{abstract}

Conclusions: Our results indicate that Toll signals are the initiating event in dorso-ventral patterning during Rhodnius embryogenesis, and this is the first report of a conserved role for Toll in a hemipteran. Furthermore, as Rp-dorsal RNA interference generates anteriorly misplaced embryos, our results indicate a novel role for Toll signals in establishment of the anterior-posterior axis in Rhodnius.

Keywords: Toll, Dorso-ventral axis, Embryogenesis, NFkB, Hemipteran

\section{Background}

Morphological diversity in the class Insecta is reflected in its different developmental modes. In addition to attaining the adult form directly (ametabolous) through complete (holometabola) or incomplete (hemimetabola) metamorphosis, the size of the embryonic rudiment relative to the

\footnotetext{
*Correspondence: rnfonseca@macae.ufrj.br; haraujo@histo.ufrj.br ${ }^{2}$ Institute of Molecular Entomology, INCT-INEM, National Institutes in Science and Technology, Macaé, Brazil

'Instituto de Ciências Biomédicas (ICB), Universidade Federal doRio de Janeiro, Av. Carlos Chagas Filho 373, Ilha do Fundão., Rio de Janeiro 21941-902 RJ, Brazil

Full list of author information is available at the end of the article
}

egg determines many of the morphogenetic events that ensue. Insect eggs are divided into long, intermediate, and short germ types according to the size of the embryonic rudiment and the number of segments that are specified before gastrulation (reviewed in [1]). This diversity of developmental modes poses challenges for understanding the molecular basis of insect development.

As a first step in embryonic development, the dorsoventral (DV) and anterior-posterior (AP) axes are specified, leading to patterned embryonic gene expression. In insects, patterning along the DV axis is required to subdivide mesodermal and ectodermal embryonic tissues 
and to drive formation of extraembryonic membranes. Two major pathways have been described that pattern the DV axis in arthropods: the Toll receptor pathway and the Bone Morphogenetic Protein (BMP) pathway. Their respective contribution to DV patterning, as well as their maternal versus zygotic functions, varies among species (see references in [2]). For instance, in the longgerm diptera Drosophila melanogaster, the maternal Toll pathway establishes domains of zygotic gene expression along the DV axis. Drosophila Toll regulates the activity of the NFkB family downstream effector protein Dorsal (Dl). Upon activation of the Toll pathway, $\mathrm{Dl}$ is no longer targeted for degradation by the Cactus/ІкB inhibitor and can translocate to the cell nuclei to regulate the expression of target genes, including localized expression of the BMP pathway genes decapentaplegic $(d p p)$ and short gastrulation (sog) (see references in [3]). In contrast, in the beetle Tribolium castaneum, which presents a more ancestral short-germ mode of embryogenesis, elements of the Toll pathway are maternally provided but most DV patterning occurs at the zygotic level [4-6]. Furthermore, BMPs play a key role in setting up the DV axis in Tribolium, and Tc-Toll does not regulate Tc-dpp expression [5,7].

Based on the conserved role of BMPs in patterning the bilaterian DV axis, it has been hypothesized that Toll was co-opted from a more ancestral immune function for DV patterning in insects [2]. Arthropod DV patterning has been studied in chelicerates such as the spider model Parasteatoda tepidariorium [8] and holometabolous insects such as Nasonia vitripennis, T. castaneum, and D. melanogaster (reviewed in [2,9]). Recently, the role of Toll and BMP pathways has been analyzed in two long germ hymenopteran species, the bee Apis mellifera and the wasp $N$. vitripennis $[10,11]$. In $N$. vitripennis the BMP gradient and its dorsally expressed target genes are not regulated by Toll signaling [11]. In A. mellifera Toll and BMP are involved not only in DV but also in AP axis establishment [10]. However, embryonic DV patterning has not been investigated in hemimetabolous insects. Considering the lack of knowledge about DV patterning in insects with a more direct (hemimetabolous) type of development, we set out to investigate the relative contributions of the Toll and BMP pathways to DV patterning in the hemimetabolous insect Rhodnius prolixus, which develops with an intermediate germ type of embryogenesis.

The hemiptera Rhodnius prolixus is an important vector of Chagas disease, which affects over 8 million people in Latin America [12]. As an established model for insect physiology, recent genomic analyses are contributing to a global understanding of $R$. prolixus genome size and organization, and tissue-specific sequences are being identified [13-15]. This community effort also provides the molecular basis for investigating the function and network of interactions between developmental genes.

Rhodnius egg production depends on blood feeding. After each blood meal, a female lays up to 40 eggs $[16,17]$. Three extracellular membranes plus a hard chorion protect the resulting embryos from desiccation [18]. While several morphological features of Rhodnius embryonic development have been described [18-21], the molecular aspects that regulate Rhodnius development remain unexplored. This is especially true for the initial embryonic stages where axial patterning events must take place, and before overall embryo morphology is set. The long-lasting effects of parental double-stranded RNA interference (pRNAi) assays recently described for this species now provide a tool for addressing these questions [22-27].

In this study, we established a staging system for early Rhodnius embryogenesis, which enabled us to correlate embryo morphology with gene expression, and provided a framework for functional studies. Next, we investigated whether the genes associated with the Toll and BMP pathways are expressed in the Rhodnius embryo, which revealed that $R p$-Toll and $R p$ - $d l$ are maternally and zygotically expressed. With this information, we performed functional analyses for Toll pathway elements. Our results suggest that the Toll pathway acts to specify germ layers along the DV axis and to localize the embryo along the long axis of the Rhodnius egg. Thus, our results implicate Toll signaling as a central pathway in Rhodnius embryonic development.

\section{Methods}

Insect rearing, tissue fixation, and histological sections

Rhodnius rearing was performed as previously described $[26,27]$. Ovary collection and dissection were performed using standard protocols available for $D$. melanogaster. Briefly, ovary fixation was performed at room temperature with $4 \%$ paraformaldehyde (PFA) for 1 hour shortly before Toll immunostaining (see below). For embryonic fixation we have established a new protocol involving trypsin digestion, sonication, and increased fixation time (detailed protocol available upon request). Briefly, the embryos were fixed at 4\% PFA in phosphate buffer $\mathrm{pH} 7.4$ with Tween$200.1 \%$ at room temperature for 24 hours, sonicated for 2 minutes, and then treated with trypsin for chorion permeabilization for 5 minutes. The next step was postfixation for 12 hours with 4\% PFA. After manual dechorionation with fine forceps, embryos were stained with DAPI $(1 \mu \mathrm{g} / \mu \mathrm{L})$. For frozen histological sections, embryos were fixed overnight in 4\% PFA, washed in PBS and included in OCT (Tissue-Tek, Sakura Finetek, Torrance, CA, USA) in 2-hour steps, from $25 \%$ to $100 \%$ OCT. Sections $(20 \mu \mathrm{m})$ were obtained in a CM 1510 S Leica cryostat (Leica, Wtzler, Germany). 
For ovary immunostaining, egg chambers were fixed for 20 minutes in 4\% PFA, washed in phosphate buffer $\mathrm{pH} 7.4$ with Tween-20 0.1\%, blocked with $0.1 \%$ normal goat serum and incubated overnight at $4{ }^{\circ} \mathrm{C}$ with primary antibody Toll d-300 (Santa Cruz Biotechnology, Santa Cruz, CA, USA, 1:50 dilution). Detection was performed with secondary anti-rabbit 488 (1:1000, 1 hour/room temperature; Alexa Fluor, Invitrogen, Life Technologies) and counterstained with Alexa 546 conjugated phalloidin (1:100, 1 hour/room temperature; Invitrogen) and DAPI. Images were obtained with a Leica SP5 confocal microscope.

\section{Identification of Bone Morphogenetic Protein- and Toll-related genes in $R$. prolixus genome and phylogenetic analysis}

$D$. melanogaster or $T$. castaneum protein sequences were used as BLAST queries in the Rhodnius prolixus unpublished genome (http://genome.wustl.edu/genomes/detail/ rhodnius-prolixus/). BLASTs were also performed in the recently published $R$. prolixus gut transcriptome [14]. After manual curation, protein sequences were aligned using the CLUSTALW algorithm available in the MEGA6 package [28]. The best substitution model for this set of Toll protein sequences $(\mathrm{LG}+\mathrm{G})$ was calculated also in MEGA6. Phylogenetic analysis of Toll-related genes was performed using a maximum likelihood method with 100 replicates for bootstrap, complete deletion of gaps and using the nearest-neighbor-interchange method.

Accession numbers for the genes analyzed were: EF1: RPRC015041; 18S, GenBank ID: AJ421962.1; $R p-d p p$, GenBank ID: GU906792.1; Rp-dl, GenBank ID: ABU96698.1; Rp-sog: RPRC015365-RA Rp-cact: Asb-31044 (VectorBase). Accession numbers for Toll genes are in main text, RPRC accession numbers are from Vectorbase (https://www. vectorbase.org/).

\section{Quantitative PCR}

Total RNA was isolated using TRIzol reagent (Invitrogen) from previtellogenic, vitellogenic, or choriogenic ovaries, and embryos collected for 6-hour time windows and aged to the periods described in the text. RNA was treated with RNAse free TURBO ${ }^{\mathrm{mm}}$ DNAse (Ambion, Life Technologies), and cDNA was synthesized from $1 \mu \mathrm{g}$ total RNA using the Multiscribe kit (Applied Biosystems. Real-time quantitative PCR was performed on a StepOnePlus real-time PCR system using power SYBR-green PCR master mix (Applied Biosystems, Foster City, USA). The comparative $\mathrm{Ct}$ method [29,30] was used to compare changes in gene expression levels. The ribosomal $18 S(18 S)$ and Elongation factor 1 (Ef1) genes were used as endogenous reference genes ([31] and Additional file 1). Primer pairs are listed in Additional file 1. All primers were designed with Primer 3 (http://frodo.wi.mit.edu/ primer3/) and checked for dimer formation with Oligoanalyzer software (www.idtdna.com/analyzer/applications/ oligoanalyzer/). All quantitative real-time PCR experiments were performed in triplicate, with four technical replicates. Bars in graphs correspond to standard error.

\section{Parental RNA interference}

Double-stranded RNA was synthesized from PCR products containing T7 promoter sequences at both ends as previously described [9]. Briefly, two successive PCRs were performed; the first to amplify $R p$ - $d l$ and $R p$-cact from the CDNA and the second PCR added T7 promoter sequences at both ends. Primer pairs are listed in Additional file 1. BLASTn against the Rhodnius prolixus genome did not detect unrelated sequences similar to the selected regions. The unrelated MalE gene (Gene ID: 948538), present in Escherichia coli, but absent from the $R$. prolixus genome, was used as a dsRNA control (dsMalE) for the off-target effects of dsRNA. The MalE $800 \mathrm{bp}$ fragment was amplified from the Litmus 281-plasmid (New England Biolabs, Iswich, MA, USA) with a single primer (T7, 5-TAATA CGACTCACTATAGGG-3) specific for the T7 promoter sequence that is on both sides of the MalE sequence. The different dsRNA concentrations used during the studies are described in Results. dsRNA injections into $R$. prolixus female virgins followed recently published protocols [23]. Two days after dsRNA injection the females were fed with rabbit blood. Oviposition and egg collection were initiated 1 week after blood feeding. Eggs were collected, counted, and the hatch rate defined after 20 days at $28^{\circ} \mathrm{C}$, to make sure all surviving embryos had hatched.

\section{Western blot}

Proteins were separated under SDS-PAGE and analyzed by Western blots using standard protocols. PVDF membranes were blocked with $5 \%$ bovine serum albumin and incubated overnight at $4^{\circ} \mathrm{C}$ with primary antibody Toll d-300 (Santa Cruz Biotechnology, 1:50 dilution). Proteins were detected with peroxidase conjugated secondary antibody (Vector; 1:4000) and Pierce ECL Western Blot Substrate (Life Technologies).

\section{Results}

Establishing a staging system to study Rhodnius prolixus early embryonic development

The hemiptera $R$. prolixus develops from an intermediate germ band, where the anlagen of the head and thoracic segments are established before gastrulation, while the abdominal segments are generated by a secondary process from a posterior growth zone. After 29 days at $21^{\circ} \mathrm{C}$ or 14 days at $28^{\circ} \mathrm{C}$ of embryonic development, a nymph hatches as miniaturized version of the adult ([20], this report). Although embryogenesis in this species has been previously characterized [19-21,32] we found it necessary 
to establish a staging system for the early embryonic stages in order to define windows for morphological and molecular analysis. Thus, we developed a fixation protocol that allows us to highlight the morphogenetic events that accompany embryogenesis from syncytial blastoderm until late stages where the cuticle is secreted (Figure 1). We divided embryogenesis into five main periods based on developmental hallmarks that have been shown to require specific gene networks in other insects. These periods included: cleavage, blastoderm, gastrulation and germ band extension, segmentation, and growth. Stages were defined as 12-hour windows, and further split into 6-hour windows for the initial stages (1 to 3 ) until the completion of gastrulation.
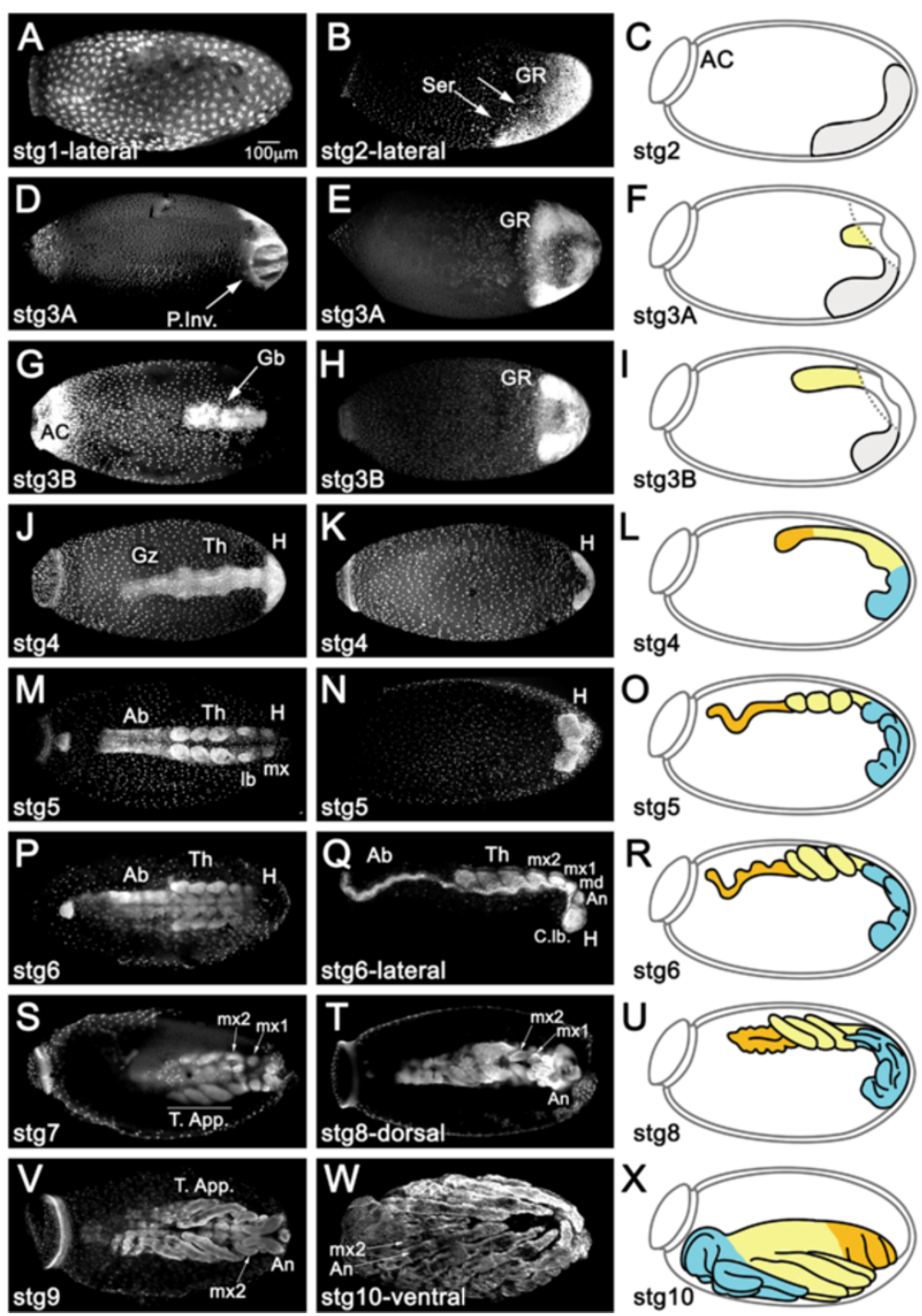

Figure 1 Prospective patterning stages in Rhodnius early embryogenesis. Nuclear staining for fixed embryos at the designated stages. Left and mid panel images are taken from the dorsal and ventral egg surface, respectively, unless stated otherwise. Drawings correspond to graphical representations of the stage in lateral views. (A) Cleavage stage embryo with nuclei at the periphery. (B,C) As the blastoderm develops, nuclei concentrate posteriorly (arrows) to form the germ rudiment (GR, grey in C). Serosal cells (Ser) are placed dorso-anteriorly. (D-F) During gastrulation, posterior invagination (P.Inv) of the GR takes places dorsally and (G-I) the germ band (Gb) extends anteriorly, while on the ventral surface the non-invaginated surface GR (grey in F) forms a horseshoe. Dashed lines in (F) and (I) correspond to the tissue under which the $\mathrm{Gb}$ invaginates. $(\mathbf{J}-\mathbf{L})$ Once gastrulation is complete, the head (H) and thorax (Th) regions are visible, as well as a growth zone (Gz) from which abdominal structures develop. (M-O) The embryo has grown to its full length. $\mathrm{H}$ and Th are segmented, but not the abdominal region (Ab). (P-R) Segmentation is complete. Ab is segmented. The abdominal caudal flexure is immersed in the yolk in (M-R) and consequently not visualized in superior optical sections. $(\mathbf{S}, \mathbf{T}, \mathbf{V})$ Growth stages in dorsal views. Cuticle fluorescence adds to and takes over nuclear staining with time. (S) Thoracic appendages (T. app.) larger than head appendages. Maxilar appendages mx1 and mx2 are distinguished. (T,U) T. app. Curved over ventral surface of the embryo. Mx1 and antennal appendages (An) grow. (V) Mx1 are hidden by An. Throughout the above stages the DV and AP axes of the embryo are inverted respective to the egg. $(\mathbf{W}, \mathbf{X})$ During katatrepsis the embryo moves backwards. As a result the embryo and egg axes coincide. Throughout stage 10 the embryo also undergoes dorsal closure. Egg anterior cap (AC); md: mandibule; C. Ib.: cephalic lobes. Magnification Bar in (A) is valid for all panels. 
DV polarity of the Rhodnius egg is easily identified immediately after oviposition $([19,20]$, this report) due to the oblique position of the anterior cap (Figure 1C). During Cleavage, the Rhodnius embryo develops as a syncytium (from 0 to 12 hours), with nuclear cleavages initially taking place at the center of the egg ( 0 to 6 hours, stage 1A). After migrating to the periphery (6 to 12 hours, stage $1 \mathrm{~B}$ ), two cell populations begin to segregate: the small syncytial blastoderm nuclei and the putative serosal cells $[33,34]$. The syncytial nuclei concentrate at the posterior pole, forming the germ rudiment (GR), which corresponds to the embryonic rudiment plus amniotic rudiment [33,35] (stage 2).

During the Blastoderm period (12 to 24 hours) membranes form around the blastoderm nuclei (by 18 hours, stage $2 \mathrm{~B}$; Figure $1 \mathrm{~B}, \mathrm{C})$ and, shortly after, the not yet invaginated ventral GR is visible as a U-shaped cubical epithelium curved around the posterior pole, likely corresponding to the prospective head lobes. Germ cells appear at this stage, projecting into the yolk [20,32].

At 24 hours (stage 3A; Figure 1D-F) gastrulation takes place, which is characterized by the invagination and inward proliferation of GR cells on the dorsal side and by the movement of the ventral part of the GR towards the posterior pole (characterizing immersion anatrepsis [33]). As a result of this movement, the amnion is formed and the embryo proper extends with the anterior cephalic end at the posterior region of the egg (stage 3B; Figure 1G-I). Thus, by the end of gastrulation the embryo and egg AP axes are inverted relative to each other [20,32]. In addition, the germ band is inverted relative to the egg DV axis and placed on the dorsal side of the egg, which differs from the pattern displayed by another hemiptera species, Oncopeltus fasciatus [36,37].

Following germ band extension, morphological Segmentation begins in the anterior region of the embryo (36 hours, stage 4; Figure 1J-L). At 48 hours (stage 5; Figure 1M-O), cephalic and thoracic appendages are visible. Segmentation of abdominal regions is visible at 60 hours (stage 6; Figure 1P-R).

Subsequent stages characterize the Growth phase, where the different appendages develop and most of the embryo, especially posterior regions, is immersed in yolk (stages 7 to 9, 72 to 108 hours; Figure 1S-V). During stage 10 the embryo undergoes the relatively rapid process of Katatrepsis (Figure 1W,X), where the embryo emerges from the yolk by rotating backwards $180^{\circ}$ [32]. As a result, the cephalic region of the embryo now aligns itself with the anterior of the egg. Similar movements are observed in most hemimetabolous insects and require the presence of the serosal membrane [33], which in Rhodnius contracts at the anterior side of the egg $[19,32]$. After stage 7 , secretion of the cuticle [26,32] disturbs tissue visualization with fluorescent nuclear staining.

In conclusion, using our fixation and staging protocol with whole mount nuclear stains, we were able to easily assess the general morphology of the embryo throughout all stages and its position relative to the axis of the egg, as well as the processes of germ band extension and segmentation (Table 1). The large amount of yolk relative to blastoderm nuclei, however, made it difficult for us to perform a detailed morphological analysis during the pre-blastoderm stage.

Table 1 Major features of Rhodnius embryonic development until katatrepsis

\begin{tabular}{|c|c|c|c|c|}
\hline \multirow[t]{2}{*}{ Period } & \multirow[t]{2}{*}{ Stage } & \multicolumn{2}{|c|}{ Developmental time at $28^{\circ} \mathrm{C}$} & \multirow[t]{2}{*}{ Characteristic features in whole mounts } \\
\hline & & Hours & $\% *$ & \\
\hline \multirow[t]{2}{*}{ Cleavage } & $1 \mathrm{~A}$ & $0-6$ & 1.8 & Nuclei divide internally \\
\hline & $1 \mathrm{~B}$ & $6-12$ & 3.6 & Nuclei reach the periphery \\
\hline \multirow[t]{2}{*}{ Blastoderm } & $2 \mathrm{~A}$ & $12-18$ & 5.3 & Formation of germ rudiment \\
\hline & $2 \mathrm{~B}$ & $18-24$ & 7.1 & Nuclei progressively concentrate at egg posterior \\
\hline \multirow[t]{2}{*}{ Gastrulation } & $3 \mathrm{~A}$ & $24-30$ & 8.9 & Germ rudiment invagination begins \\
\hline & $3 B$ & $30-36$ & 10.7 & Germ band extension \\
\hline \multirow[t]{4}{*}{ Segmentation } & 4 & $36-48$ & 14.3 & Anterior segmentation (in head and thorax) begins \\
\hline & 5 & $48-60$ & 17.9 & Appendage buds appear; non-segmented abdomen \\
\hline & 6 & $60-72$ & 21.4 & Appendages grow; \\
\hline & & & & segmented abdomen; neural groove evident \\
\hline \multirow[t]{3}{*}{ Growth } & 7 & $72-84$ & 25 & Thoracic appendages elongate, bigger than head appendages \\
\hline & 8 & $84-96$ & 26.6 & Antennal appendages grow over first maxillary appendages \\
\hline & 9 & $96-108$ & 32 & $\begin{array}{l}\text { First maxillary appendages hidden by antennal appendages; } \\
\text { embryo shortens and widens (germ band retraction) }\end{array}$ \\
\hline Katatrepsis and Dorsal Closure & 10 & $108-132$ & 35 & $\begin{array}{l}\text { At the end of katatrepsis, embryo and egg anterior-posterior } \\
\text { axes coincide; embryo closes dorsally }\end{array}$ \\
\hline
\end{tabular}




\section{Several Toll and Bone Morphogenetic Protein pathway components are conserved in Rhodnius}

In order to address which genes are required to pattern the Rhodnius DV axis, we first sought to identify Toll and BMP pathway genes that may be expressed during embryogenesis. We recently identified complete or partial sequences for genes in both pathways, including six different Toll sequences in the $R$. prolixus genome. Expression was confirmed for most of these in the recently published $R$. prolixus transcriptome raw data [14]. Phylogenetic analysis suggests that Rp-Toll-like-2 (RPRC009262), herein referred to as Rp-Toll, is a Drosophila Toll ortholog (Figure 2A). The Rp-Toll sequence was aligned to Drosophila and Tribolium Toll proteins, which revealed that this sequence comprises a transmembrane region, part of the extracellular segment and most of the intracellular domain that interacts with downstream elements (Figure $2 \mathrm{~B}$ and Additional file 2). The predicted $R p$-Toll protein sequence presents $44 \%$ sequence identity with Drosophila Toll, and most of this identity covers the region identified by the anti-Dm-Toll antiserum used in this study (Figure 2B and Additional file 2).

Sequences coding for a Dorsal transcription factor (an $\mathrm{NF} \kappa \mathrm{B} / \mathrm{c}-$ Rel protein activated by Toll) have been previously identified in $R$. prolixus [38]. These authors detected $R p-d l$ transcripts in the embryo $(d l, 1 \mathrm{~A})$ as well as adult salivary glands, midgut, and fat body ( $d l, 1 \mathrm{~B}$ and $1 \mathrm{C})$. Accordingly, we identified an inhibitory cactus/IkB ortholog that is expressed in R. prolixus ovaries, embryos, fat body, and in the digestive tract.

BMP family proteins signal through heterodimeric transmembrane receptors to induce phosphorylation of $\mathrm{R}$-Smads, leading to activation of Co-Smads and regulation of gene transcription. Classically, BMPs are regulated in the extracellular space by binding to Chordin (Chd)/Short gastrulation (Sog) antagonists. We have identified in the $R$. prolixus genome two sequences coding for BMP ligands ( $R p-d p p$ and $R p-g b b)$ and one sequence for the antagonist Sog $(R p-s o g)$. Furthermore, one type I $(R p-t k v)$ and one type II (Rp-punt) BMP receptor, two R-Smads (Rp-mad and Rp-mad-like), and one Co-Smad (Rp-medea) are represented as expressed sequences, implying that all elements necessary for BMP signaling are present (Mesquita and colleagues, manuscript in preparation). Given that Dpp/BMP and Sog/Chd sequences have been previously associated to embryonic DV patterning in arthropods and vertebrates, we chose to investigate these homologs in greater detail.

\section{Expression of Toll and Dpp pathway genes varies throughout embryonic development}

In order to investigate whether Toll and BMP pathway genes may play a role in embryogenesis, we used quantitative real-time PCR to characterize their expression from embryonic stages 1 to 4 . Given that early embryogenesis frequently depends on maternal messages, we also analyzed expression during oogenesis. For all time points analyzed, we normalized mRNA levels to two reference genes, which revealed similar variation patterns (see Methods for details) [31]. We found that $R p$-Toll mRNAs are present during the early stages of cleavage and increase during formation of the GR (Figure 3A). Rp-Toll is also expressed in the ovaries, indicating that the mother may provide the messages detected during stage $1 \mathrm{~A}$ (Figure 3A). We observed similar Rp-Toll mRNA levels in 0 - to 6-hour embryos and unfertilized eggs, confirming that these messages are maternally provided (Figure 3F).

We then sought to determine the expression of the Toll protein during Rhodnius embryogenesis. To this end, we employed a specific antibody directed against the Drosophila Toll (see Methods). In agreement with the high degree of sequence identity between Rp-Toll and Dm-Toll, we show that the Dm-Toll antibody crossreacts with the Rhodnius homologous protein in Western blot assays. Toll protein expression during embryogenesis (Figure 3B) is consistent with Rp-Toll mRNA expression, with the highest protein levels observed during early cleavage and during gastrulation through germ band extension. However, the low mRNA levels observed during embryonic cleavage suggest that the large amount of protein at this stage derives from maternal $R p$-Toll messages that are delivered to the embryo where high rate translation takes place. Alternatively, maternal protein is loaded into the oocyte and future embryo. The latter hypothesis is consistent with the ovarian Toll protein pattern observed in this study. To investigate whether Toll protein in early cleavage embryos could result from protein transferred from the mother during oogenesis, we performed immune labeling in Rhodnius egg chambers. We observed Rp-Toll protein in the tropharium and vitellarium, in the plasma membrane of follicle cells and developing oocytes (Figure 4). Staining in oocytes probably originated from the nurse cells through trophic cords. This staining is specific as it was lost in Rp-Toll knockdowns (Additional file 3).

Since it is a putative effector of the Toll pathway, we investigated the expression of $R p-d l$ during oogenesis and embryogenesis (Figure $3 C$ ). Similarly to $R p-T o l l, R p-d l$ is expressed during oogenesis and low-abundance $R p$ - $d l$ transcripts are detected during cleavage stages. Significant expression is seen during stages $3 \mathrm{~A}$ and $\mathrm{B}$ of gastrulation, which coincides with the increase in Toll expression (Figure 3A). At 18 to 24 hours (stage 2B), $R p$-Toll and $R p$ - $d l$ transcript levels are increased relative to unfertilized eggs (Figure 3F-G). Thus, peak mRNA levels at the subsequent stage 3 correspond mostly to zygotic expression. Accordingly, the putative NFkB inhibitor Rp-cact is expressed in ovaries and displays constant expression levels throughout embryogenesis Figure 5A. It 


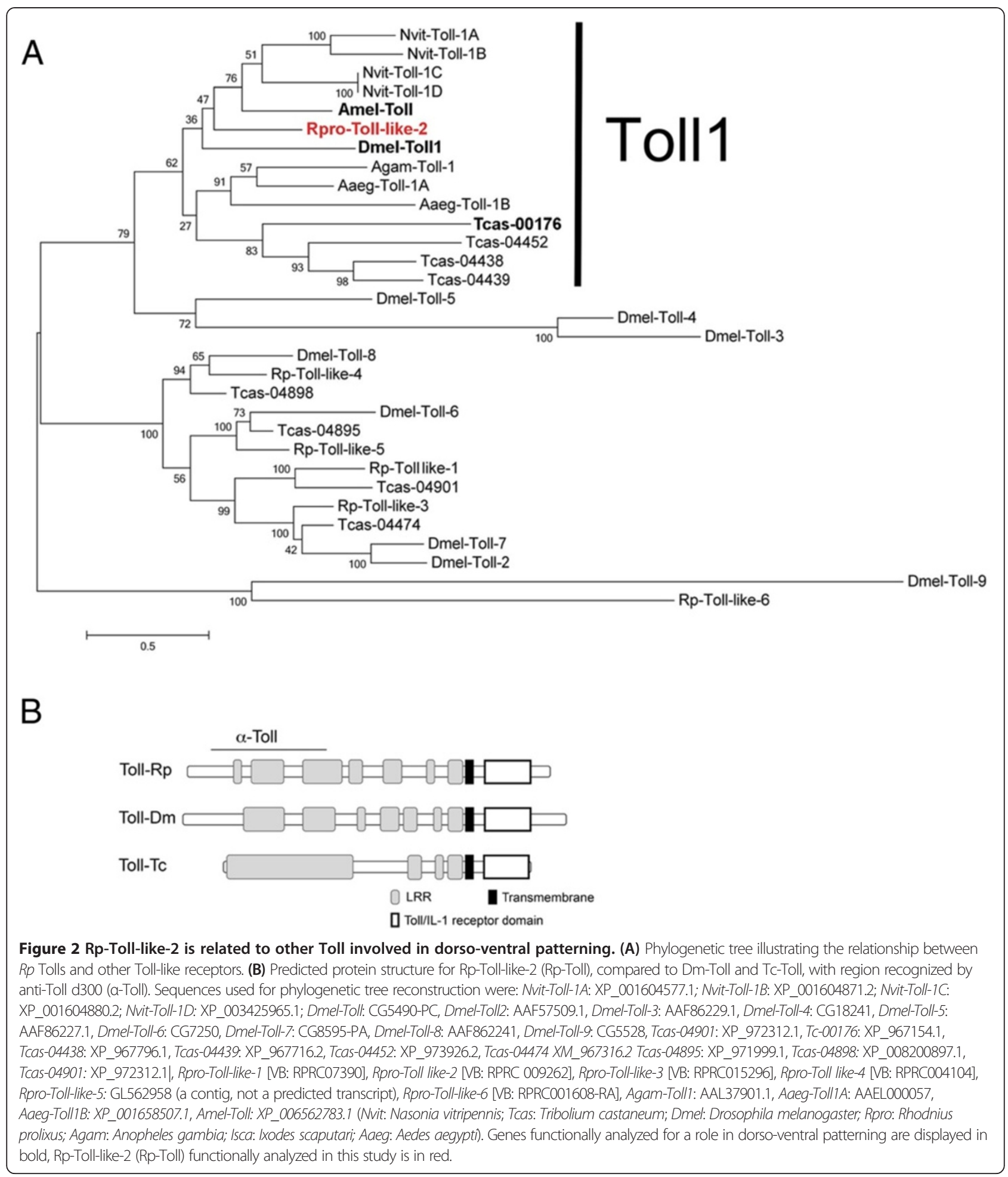

is also expressed in the fat body and midgut Figure 5C, two important tissues for the innate immune response. These results suggest that $R p$-cact may respond to maternal and zygotic Toll signals in the embryo.

As part of the BMP pathway, Rp-dpp expression, on the other hand, was only observed at the onset of gastrulation (Figure 3D, Additional file 4). This pattern is different from $R p$-sog (Figure 3E), which is expressed at low levels during early stages and coincides with peak $R p$-Toll and $R p$ - $d l$ zygotic expression. High $R p$ - $d p p$ and $R p$-sog mRNA levels in stages $2 \mathrm{~B}$ and 3 result from zygotic expression, given that these peaks are not observed 


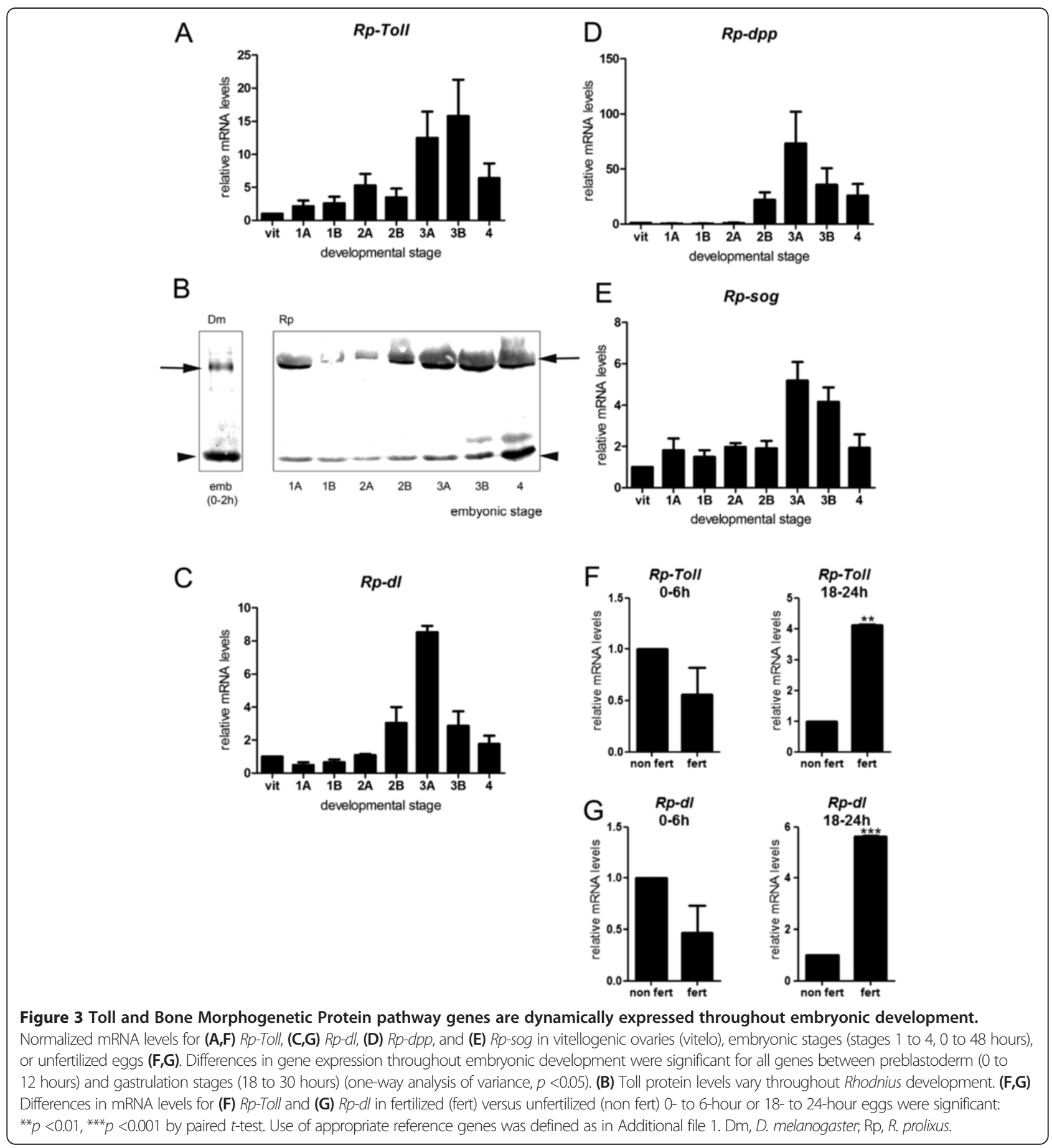

in unfertilized eggs (data not shown). Therefore, it is unlikely that maternal $R p$ - $d p p$ mRNA provides information for early patterning in Rhodnius.

\section{$R p-d l$ knockdown alters embryonic patterning}

Based on the pattern of $R p$-Toll and $R p$ - $d l$ expression in early embryos, we decided to investigate their putative functional role in early embryonic patterning. To this end, we performed pRNAi assays for $R p-d l$, the sole Toll pathway effector. Females were injected with different concentrations of $R p-d l$ or the unrelated MalE dsRNA control (as described in [26,39]). Egg laying and female survival were not affected after $R p-d l$ pRNAi (Table 2). On the other hand, a severe (98\%) decrease in $R p$ - $d l$ mRNA levels led to a 95\% reduction in the embryo hatch rate (Table 3). Over $40 \%$ of non-hatching embryos resulted from halted development during the early stages, since no germ rudiment was observed, while the majority 

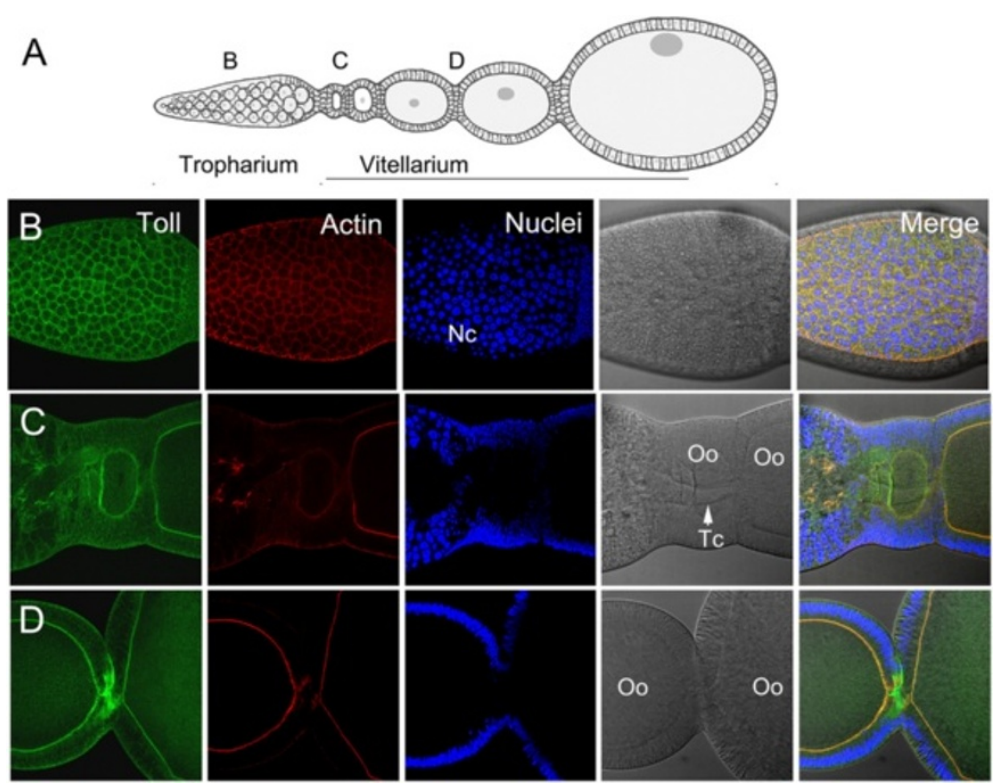

Figure 4 Toll protein is maternally delivered to developing oocytes. (A) Rhodnius oogenesis showing the tropharium (B), early (C), and late (D) oocytes in vitelarium. Chorionic stages are not displayed. (B) Toll protein is present in follicle cells of the tropharium. (C) Toll in early oocytes is likely delivered from nurse cells through trophic cords. (D) Protein in late oocyte cytoplasm and plasma membrane. Toll protein in green, actin to reveal cell perimeter in red, nuclei DAPI stain in blue. Nc: nurse cells; Oo: oocyte; Tc: trophic cord.

was comprised of embryos with altered morphologies (Table 4$)$. When we analyzed $R p$ - $d l$ pRNAi embryo morphology, we observed that during blastoderm stages the GR was frequently located at the anterior portion of the egg. Interestingly, diagonal placement of the GR was lost and replaced by perpendicular placement relative to the egg's long axis (Figure 6A,B). Rp-Toll pRNAi lowered the amount of protein in developing oocytes (Additional file 3 ) and resulted in embryonic phenotypes that resemble $R p$ - $d l$ pRNAi embryos (Table 4 ).

$R p$ - $d l$ pRNAi embryos that reach the segmentation stages are short and mostly mislocalized to the anterior region of the egg (Figure $6 \mathrm{C}-\mathrm{H}$ ). These embryos present a tube-like structure similar to that of $T c-d l$ RNAi embryos, which lack mesodermal cells [5]. Thus, we performed cross-sections of $R p$ - $d l$ pRNAi embryos, and confirmed that they lack an internal (most likely mesodermal) layer (Figure 6I,J). No extraembryonic amnion covering the embryo was observed either. Furthermore, we observed mild $R p$ - $d l$ pRNAi phenotypes in $25 \%$ of segmentation stage embryos which were characterized by the presence of vestigial appendages directed towards the surface of the egg (Figure 6E-H). Similar phenotypes have been seen for spider embryos under $s o g$ pRNAi, which have been suggested to result from the loss of ventral structures [8]. This interpretation is also consistent with the decrease in $R p$-sog expression we observed during stage $2 \mathrm{~B}$ caused by $R p$ - $d l$ pRNAi (see below, Figure 7). Likewise, we observed a decrease in
$R p$-sna and Rp-twi mRNA levels in $R p$ - $d l$ knockdowns (Figure 6K). Therefore, the phenotypes resulting from loss of Toll signals may be due to loss of ventral embryonic territories.

On the other hand, parental RNAi for $R p$-cact results in oogenesis phenotypes that preclude embryonic formation: (Figure 5). In order to unveil the role of cactus during Rhodnius embryogenesis, we performed pRNAi on adult females. Intriguingly, $R p$-cact dsRNA-injected females showed underdeveloped ovaries and large undigested gut contents 1 week after blood feeding (Figure 5F, data not shown). In contrast, control dsRNA-injected females display ovaries at the choriogenic stage and largely absent gut content (Figure 5E, data not shown). After $R p$-cact dsRNA, female adult mortality increased with time and reached $100 \%$ after 10 days, even when a low dsRNA concentration was adopted for the pRNAi assay $(<100 \mathrm{ng} / \mu \mathrm{L})$. The low number of eggs laid by surviving females (Table 3 ) precluded the analysis of possible Rp-cact during DV formation. Similar adult lethality has been observed in experiments investigating Tc-cact in the beetle Tribolium [5]. Only the injection of embryonic RNAi, as done in Tribolium, would be able to unveil the role of $R p$-cact during DV axis formation, a technique not yet applied in Rhodnius due to its hard chorionic structure. This suggests that $R p$-cact has additional functions that may not involve $R p$ - $d l$ or that excess Toll signals are more deleterious to oogenesis than lack of Toll. 

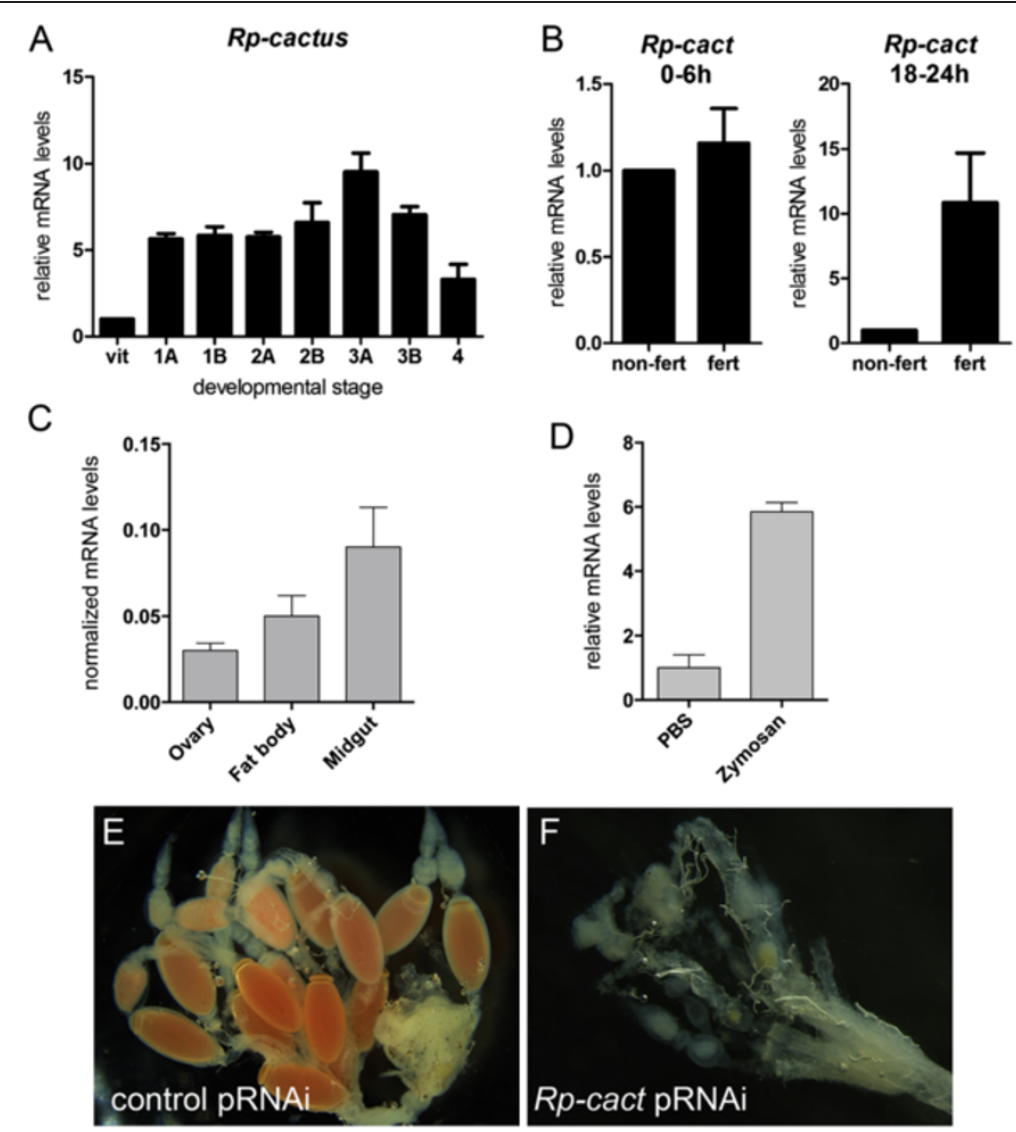

Figure 5 Rp-cact expression and knockdown phenotypes. (A) Normalized mRNA levels for Rp-cact show small variability throughout embryonic development. (B) Rp-cact mRNAs in stage $1 \mathrm{~A}$ embryos (0 to 6 hours) are mostly maternally provided, while gastrulation stage $2 \mathrm{~B}$ (18 to 24 hours) mRNAs are generated zygotically, since levels of the former are unaltered, while the latter are decreased in unfertilized eggs (non fert). (C) Rp-cact is also expressed in the immune tissues of the midgut and fat body. (D) In immune tissues such as the gut, Rp-cact levels respond to activation of the Toll pathway using zymosan. (E,F) Ovaries resulting from control MalE (E) or Rp-cact (F) pRNAi show that egg chambers do not develop in the Rp-cact knockdown.

$R p-d l$ regulates expression of the Bone Morphogenetic Protein pathway gene $R p$-sog

In order to investigate hierarchical relationships between Toll and BMP pathway genes during embryogenesis, we analyzed the expression of $R p$-Toll, $R p$-cact, $R p$-sog, and $R p$ - $d p p$ under $R p$ - $d l$ pRNAi. Functional assays for $R p$ - $d l$ showed that a 60 to $80 \%$ decrease in $R p$ - $d l$ mRNA levels (Figure 7) results in an approximately 60\% decrease in stage $2 \mathrm{~B} R p$-sog and $R p$-cact mRNAs, while stage 1 mRNA levels are unchanged (Figure 7 ). In contrast, no

Table 2 Egg lay resulting from parental RNA interference

\begin{tabular}{lcc}
\hline dsRNA $(\boldsymbol{\mu g} / \boldsymbol{\mu l})$ & $\begin{array}{c}\text { Egg lay } \\
\text { (per female per feeding) }^{\boldsymbol{\dagger}}\end{array}$ & $\begin{array}{c}\text { Number } \\
\text { of females }\end{array}$ \\
\hline Rp-dl (0.5) & $31.88 \pm 5.35$ & 28 \\
Rp-cact $(0.5)^{*}$ & $3.5 \pm 1.25$ & 10 \\
Rp-cact $(1.0)^{*}$ & $0.96 \pm 0.26$ & 20 \\
Rp-Toll $(0.5)$ & 38.5 & 25 \\
Control $(0.5)$ & $26.0 \pm 1.38$ & 20 \\
\hline
\end{tabular}

${ }^{\dagger}$ Values are average \pm standard deviation. ${ }^{*} p<0.01$, versus control. significant changes in stage 1 mRNA levels were seen for $R p$-dpp, $R p$-cact, and $R p$-Toll under the same condition (Figure 7). No differences are observed for $R p-d p p$ and $R p$-Toll at later stage $2 \mathrm{~B}$ either. Stage $2 \mathrm{~B}$ mRNAs are likely composed of zygotic messages, since levels are greatly reduced in unfertilized embryos, while stage 1 mRNAs are in great part provided by the mother. Our

Table 3 Embryo viability resulting from parental RNA interference

\begin{tabular}{lcc}
\hline dsRNA $(\boldsymbol{\mu g} / \boldsymbol{\mu l})$ & Embryo viability $(\%)^{\dagger}$ & Number of eggs \\
\hline$R p-d l(0.25)$ & 58.51 & 135 \\
$R p-d l(0.5)^{*}$ & $5.5 \pm 2.03$ & 801 \\
$R p-d l(1.0)^{*}$ & $1.55 \pm 0.184$ & 400 \\
$R p-\operatorname{cact}(0.5)^{*}$ & $3.37 \pm 1.71$ & 89 \\
$R p-\operatorname{cact}(1.0)^{*}$ & 0 & 123 \\
$R p-T o l l(0.5)$ & 0.59 & 168 \\
Control $(1.0)$ & $89.54 \pm 5.03$ & 514 \\
\hline${ }^{\dagger}$ Values are average \pm standard deviation. ${ }^{*} p<0.01$, versus control.
\end{tabular}

${ }^{\dagger}$ Values are average \pm standard deviation. ${ }^{*} p<0.01$, versus control. 
Table 4 Embryonic phenotypes resulting from $R p$-dl pRNAi

\begin{tabular}{|c|c|c|c|c|c|}
\hline \multirow{2}{*}{ dsRNA $(\mu \mathrm{g} / \mu \mathrm{l})$} & \multicolumn{4}{|c|}{ Embryonic phenotypes (\%) } & \\
\hline & No germ rudiment* & Embryo anteriorly localized ${ }^{* *}$ & Embryo randomly localized & Embryo posteriorly localized & \\
\hline$R p-d l(0.5)$ stages $2-4$ & 44 & 50 & 5 & 0 & 18 \\
\hline$R p-d l$ (1.0) stages 2-4 & 32 & 52 & 4 & 12 & 25 \\
\hline Rp-dl (0.5) stages 5-10 & 22 & 68 & 7 & 3 & 59 \\
\hline Rp-Toll (0.5) stages 2-10 & 7 & 23 & 30 & 40 & 30 \\
\hline control (1.0) stages 2-10 & 6 & - & - & 94 & 50 \\
\hline
\end{tabular}

*“No germ rudiment" phenotype includes empty eggs and halted embryos that do not form a germ rudiment. **At stage 2 embryos anteriorly localized display embryonic rudiment perpendicular to long axis of egg; after stage 5 anteriorly localized embryos are short, with absent or small appendage-like structures ( $25 \%$ penetrant appendage-like phenotype).

results strongly suggest that zygotic $R p$-sog and $R p$-cact expression during gastrulation (stage $2 \mathrm{~B}$ ) may depend on the activity of the Toll pathway.

\section{Discussion}

\section{$R p$-Toll is a conserved insect Toll ortholog}

In this study, we sought to identify and perform functional analyses of genes required for DV patterning in the hemipteran Rhodnius, with the goal of better understanding the evolution of DV patterning in metazoans.

We identified six coding sequences for Toll-related receptors in the $R$. prolixus genome and gut transcriptome (Mesquita and colleagues, manuscript in preparation and [14]), and phylogenetic analysis showed that $R p$ Toll-2 is the Toll ortholog associated with DV patterning during embryogenesis (Figure 1).

In addition to Toll, Drosophila expresses eight other Toll-related receptor genes that perform redundant or partially redundant functions [40-42]. Phylogenetic analysis of Toll receptors in the mosquito Anopheles gambiae, the beetle Tribolium castaneum, the bee Apis mellifera, the fruit fly Drosophila melanogaster, and the bug Oncopeltus fasciatus showed major variation among these species [43-45]. In addition, it has been established that Toll loci involved in embryonic DV patterning are part of an orthologous group in all insect species studied so far. Therefore, the presence of several Toll loci, but only one true Toll ortholog, indicates that the $R$. prolixus genome displays a repertoire of Toll receptors that is characteristic of insects.

In contrast to the receptor diversity, intracellular Toll pathway components appear less diversified in insect evolution. Toll adaptors such as MyD88, Tube, and Pelle display one-to-one orthologs in $R$. prolixus and other insects ([45]; data not shown). Furthermore, a single IкB Cactus ortholog was identified in the $R$. prolixus genome (this report, [38]). A dorsal immune factor (dif) ortholog, which codes for a second Rel-like protein in Drosophila, is absent in other insects as well as in the $R$. prolixus $s$ genome (M. Sorgine, unpublished results). Thus, Rp-dl and Rp-cact should be effector and inhibitor, respectively, of all Toll functions in $R$. prolixus.
Toll signals pattern the Rhodnius embryonic dorso-ventral axis

Next, we analyzed the effects of parental knockdown on downstream elements of the Toll pathway. Because of the challenges associated with performing embryonic in situ hybridization in Rhodnius, we conducted an alternative staging protocol, which allowed us to correlate changes in pRNAi gene expression with temporally specific morphological phenotypes. This protocol can be used in future functional analyses conducted during early Rhodnius embryogenesis.

$R p$ - $d l$ pRNAi embryos that reach gastrulation stages lack an internal mesodermal layer, which is consistent with a role for Toll signals in DV patterning, as shown for several insect species. Loss of extraembryonic tissues, as shown in our $R p-d l$ knockdowns, has also been associated with defective DV patterning [34,36,46-48]. Furthermore, the perpendicular placement of the GR in blastoderm stage $R p-d l$ pRNAi embryos is reminiscent of Tc-Toll and Tc-sog pRNAi embryos, where it has been suggested that the Toll pathway harbors an AP as well as DV component [5]. Our molecular analysis showed that $R p$-Toll and $R p$ - $d l$ are expressed during oogenesis and embryonic cleavage stages, and that the mother delivers a great part of the $R p$-Toll and $R p$ - $d l$ mRNAs for use during embryogenesis. A second peak of Rp-Toll (24 to 36 hours) and $R p$ - $d l$ (18 to 30 hours) mRNAs resulting from zygotic expression is observed at gastrulation. Thus, the fundamental question is whether the DV patterning phenotypes observed under $R p-d l$ pRNAi are due to blockage of maternally or zygotically provided $R p$-dl and Rp-Toll.

Maternal messages are fundamental for the development of insect embryos. For example, maternal messages via the Epidermal Growth Factor Receptor pathway break the symmetry in Drosophila, Nasonia, and Tribolium and Gryllus bimaculatus ovarian follicles [49], setting up the embryonic DV axis. In Drosophila, this symmetry-breaking event leads to the differential activation of maternally provided Toll receptors along the DV axis, which is translated into the nuclear Dorsal gradient 

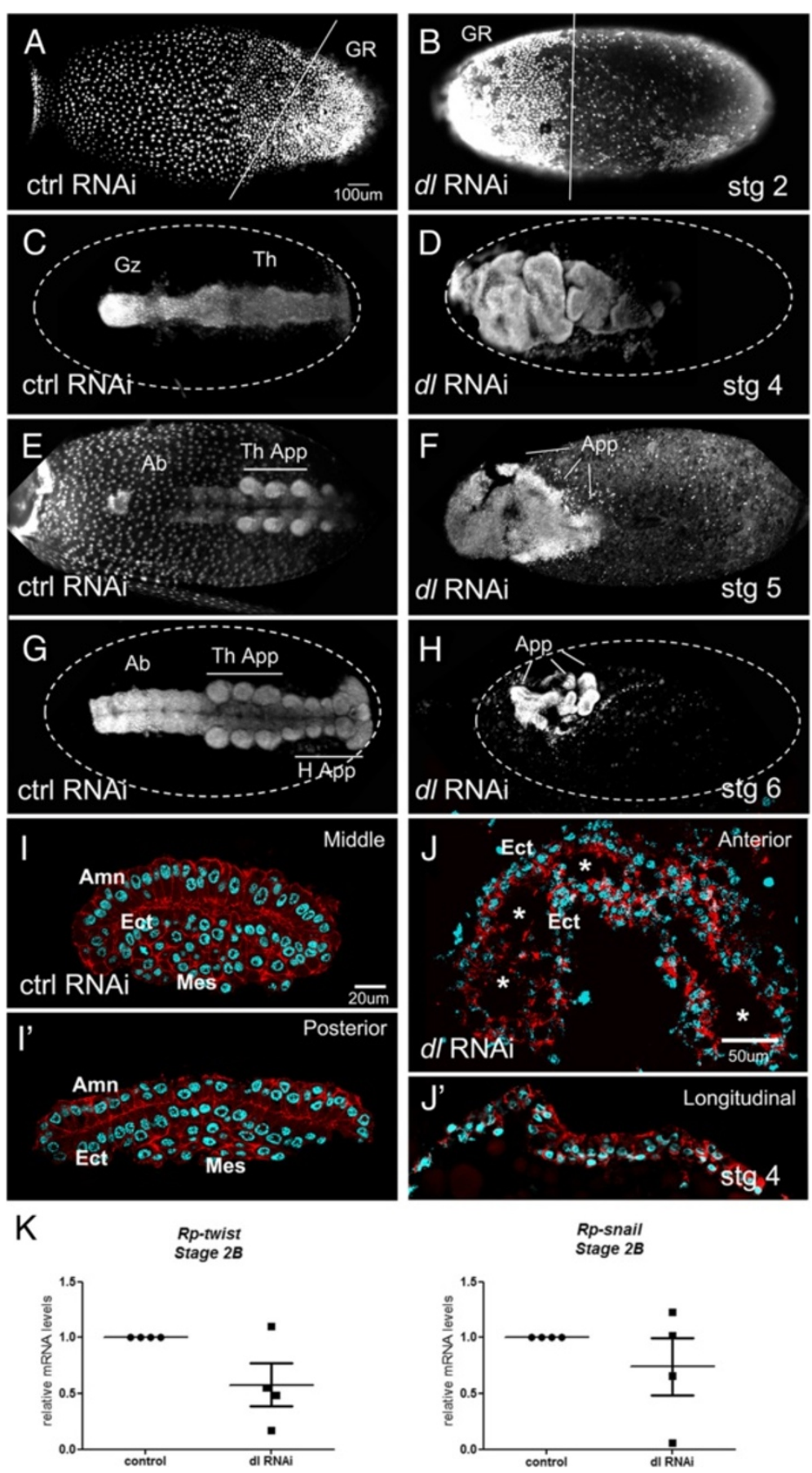

Figure 6 (See legend on next page.) 
(See figure on previous page.)

Figure 6 Rp-dl knockdown embryonic phenotypes. Embryos resulting from control $(\mathbf{A}, \mathbf{C}, \mathbf{E}, \mathbf{G}, \mathbf{I})$ or $R p-d l(B, D, F, H, J)$ parental RNA interference (pRNAi). (A,B) At the blastoderm stage control (ctrl) embryos present a posteriorly localized germ rudiment (GR) that is diagonally displayed (A, as in Figure $2 \mathrm{~B}$ ), while the Rp-dl RNAi GR is anteriorly localized and perpendicular to the egg's long axis. (C,D) After gastrulation the head, thorax (Th), and growth zone (Gz) are seen in control (C) MalE RNAi embryos, but are not distinguished in (D) the Rp-dl RNAi. (E,F) Stage 5 and (G,H) stage 6 embryos show the correct formation of appendages in control $(E, G)$ MalE RNAi embryos, while $(\mathbf{F}, \mathbf{H})$ Rp-dl RNAi embryos present only appendage-like structures (App.) that are seen in 25\% of cases. These structures cannot be identified as head (H.App.) or thoracic appendages (Th. App.). Ab, abdomen. (I-J') After gastrulation, amnion (Amn), ectodermal (Ect) and mesodermal (Mes) layers are distinguished in control embryo transverse sections stained with Alexa 647-phalloidin and nuclear Hoescht (I,II). Shown are embryo sections in the middle (I) and posterior (I') regions of the egg. Rp-dl RNAi (J,J') embryos placed at the egg anterior form a hollow tube (Ect) with no distinguishable mesodermal layer, as seen in transverse (J) and longitudinal ( $\left.\mathbf{J}^{\prime}\right)$ sections. Note that these embryos are localized adjacent to the egg surface. The asterisks in J point to the hollow embryo interior. Lateral view of embryos in (A,B; A slightly tilted ventrally), dorsal view in (C-H). However, embryo dorso-ventral placement in Rp-dl RNAi is randomized. (K) Relative mRNA levels for mesodermal genes in control and Rp-dl RNAi embryos (four biological replicates). Rp-twist and Rp-snail show a tendency to decrease in Rp-dl knockdowns.

during embryogenesis. Indeed, in this diptera, Toll, dorsal, and cact functions in DV axis formation are exclusively maternal [50].

However, positional information derived from the mother is not a strict requirement. For instance, exposure of Atrachya beetle embryos to cold temperatures leads to the production of germ bands that are randomly condensed relative to the AP and DV axes [51], implying that axial patterning is regulated zygotically in this species. Moreover, careful investigation of DV axis establishment in T. castaneum showed that Toll and $\mathrm{Dl}$ are involved in a zygotic self-regulatory circuit [5]. Evidence for this circuit was provided by the comparison of spatial expression patterns of DV target genes in embryonic versus parental RNAi of Tc-Toll, Tc-dorsal, and Tc-cactus. Embryonic and parental knockdown phenotypes are identical in T. castaneum, strongly suggesting that most DV patterning events take place at the zygotic level.

Unfortunately, we were unable to reproduce this level of spatial resolution in the expression of DV genes in
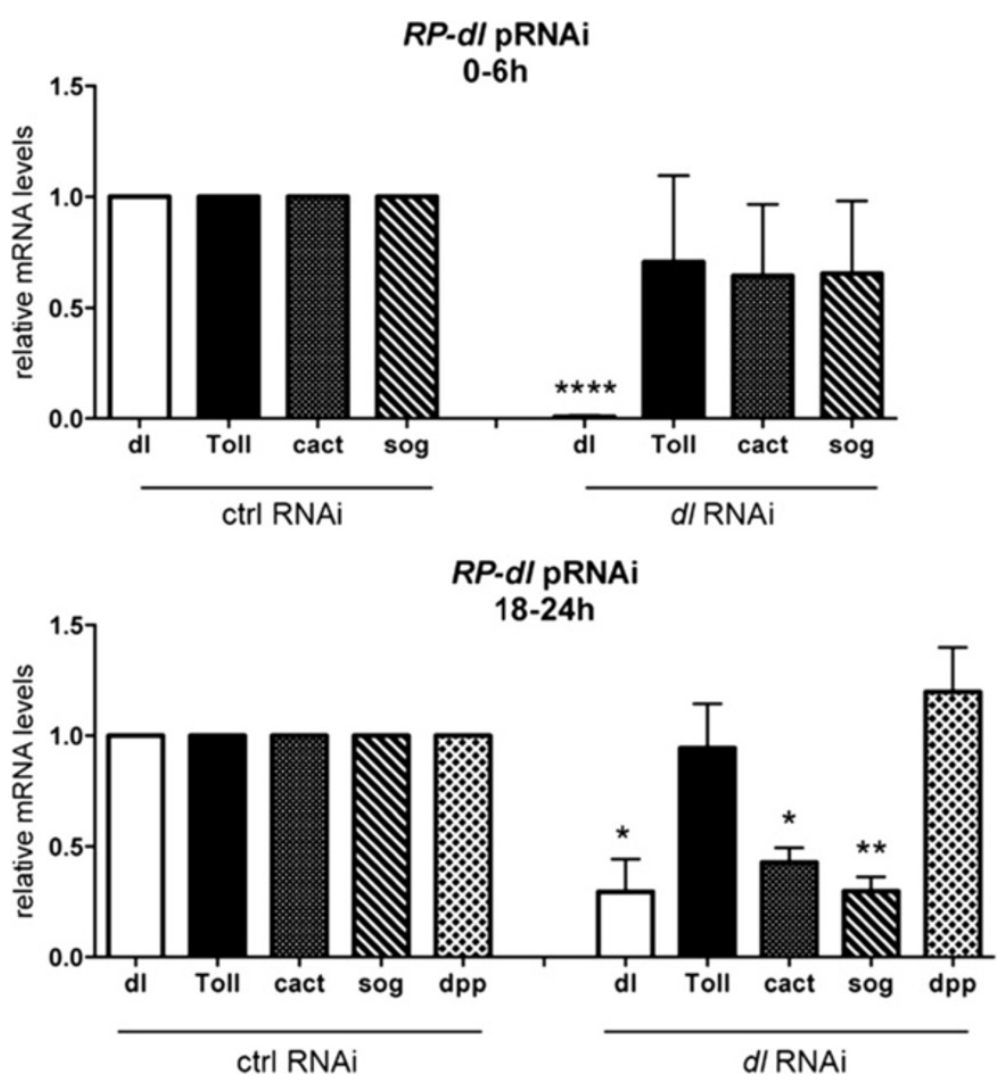

Figure $7 R p$-sog and $R p$-cact mRNA levels are regulated by $R p$-dl. Normalized mRNA levels for Rp-dl, Rp-Toll, Rp-cact, Rp-sog, and Rp-dpp in control mal parental RNA interference (pRNAi) or Rp-dl pRNAi $(0.5 \mu \mathrm{g} / \mu \mathrm{L})$ embryos were evaluated at stage 1 ( 0 to 6 hours) and stage $2 B$ (18 to 24 hours) embryonic development. ${ }^{*} p<0.05,{ }^{* *} p<0.01,{ }^{* * * *} p<0.0001$ by paired $t$-test. 
Rhodnius since we were not able to reproduce the previously published in situ protocols [23,24] and embryonic injections are remarkably difficult to administer due to the hard chorion of Rhodnius. However, at the morphological level, early misplacement of GR cells in the anterior of the egg under $R p-d l$ pRNAi suggests that the maternal Toll pathway performs an early axial patterning function that affects later developmental stages. Furthermore, perpendicular placement of the GR relative to the long axis of the egg under $R p$ - $d l$ pRNAi resembles the loss of DV polarity phenotype reported for Tc-Toll and $T c-d p p$ [5], suggesting an early effect of $R p-d l$ in DV patterning. During the early stages, the decrease in $R p$ - $d l$ mRNA levels under RNAi is greatest (>90\%), with most resulting embryos (84\%) being anteriorly misplaced and short. Therefore, it is reasonable to suggest that DV patterning is controlled by maternal $R p-d l$.

In conclusion, while zygotic Tc-Toll seems to be the central player in Tribolium DV patterning, and the role for Drosophila Toll in embryonic patterning is exclusively maternal, maternal $d l$ in both insects regulates establishment of the DV axis. Our results support the notion of a conserved DV patterning function for maternal $R p$-dl. Furthermore, the major differences between DV patterning among these three species seem to reside in the maternal versus zygotic contribution of Toll signals, and the presence or absence of positive feedback loops (Figure 8).

\section{Rhodnius Toll signals play a novel role in defining the embryo's position along the anterior-posterior axis} Interestingly, our functional assays reveal that $R p-d l$ pRNAi leads to a severe defect in the positioning of the developing embryo, which is found at the anterior of the egg instead of being placed at the posterior. This observation strongly suggests that the Toll pathway exerts a role not only in the establishment of the DV axis, but also in the AP axis. The embryo's anterior placement could result from incorrect specification of extraembryonic membranes, since we observed a small number of amniotic cells in $R p$ - $d l$ RNAi embryos. However, we observed misplaced embryos as early as the syncytial blastoderm stages, before extracellular membranes are able to exert a tracking effect on the developing embryo. Therefore, an alternative hypothesis is that specification of the AP and DV axes are interdependent and that $R p$ $d l$ RNAi interferes with the expression of AP patterning genes. A recent study reported that patterning of the two major body axes is co-dependent in Apis mellifera. Considering that we found $R p$ - $d l$ pRNAi embryos mislocalized along the AP axis, a similar mechanism may play a role during axis specification in Rhodnius [10].

Anteriorly placed Rhodnius embryos are short and do not emerge into the yolk, suggesting that anatrepsis has been disturbed. Such an effect has not been previously described for the Toll pathway in any of the arthropod species analyzed to date. However, it has been recently reported that interfering with the terminal system in the hemipteran Oncopeltus disturbs invagination of the blastoderm although, in this case, germ band extension and segmentation proceeds almost normally [52]. This is consistent with the interpretation that part of the phenotypes displayed by interfering with the Toll pathway in Rhodnius may result from AP patterning defects.

\section{Respective contribution of the Toll and Bone \\ Morphogenetic Protein pathways to Rhodnius dorso-ventral patterning}

A long-standing question in embryonic patterning concerns identifying the point in evolution at which the two main pathways (Toll and BMP) were deployed to pattern the DV axis, as well as elucidating their respective contributions along different clades. Studies in ancestral arthropod classes (for example, the crustacean Parhyale hawaiensis [53] and the spider Parasteatoda tepidariorum [8]) indicate no role of Toll in DV patterning, although Toll is detected during embryogenesis of the tick Riphicephalus (Boophilus) microplus [54]. In fact, in these arthropods, BMPs seem to perform a more central role in setting the DV axis.

The role of Toll in immunity has been functionally assayed in several insects (see references in [55]), unlike its role in DV patterning, which has only been studied in a few holometabolous insects $[2,10,56]$ and more recently in Oncopeltus (J.A. Lynch and S. Roth, personal communication). The functional analyses of $R p$ - $d l$ conducted in this study show that the Toll pathway plays a role in Rhodnius embryogenesis. However, $R p$ - $d l$ and $R p$-cact are also expressed in the salivary gland, intestine, and fat body, where they play a role in the response to infection ([38], this report). Therefore, considering the hypothesis that the ancestral function of the Toll pathway is in immunity [2], our results support the notion that acquisition of an embryonic role for Toll predates the common ancestor of hemiptera and hymenoptera.

The relative contribution of the Toll and BMP pathways to DV patterning varies across species. In vertebrates, BMPs perform a central role in setting the DV axis, and no functional role for an NFKB pathway in this context has been reported [57]. In insects, sequences that respond to Dorsal/NFkB have been identified, which drive DV restricted expression patterns in Anopheles, Drosophila, and Tribolium [46,58-61]. In Drosophila, maternal Toll signals play the greatest role in defining territories along the DV axis, spatially restricting the zygotic expression of target genes such as $d p p$ and sog. Sog and Dpp proteins subsequently subdivide the dorsal domain and drive the formation of the extraembryonic 

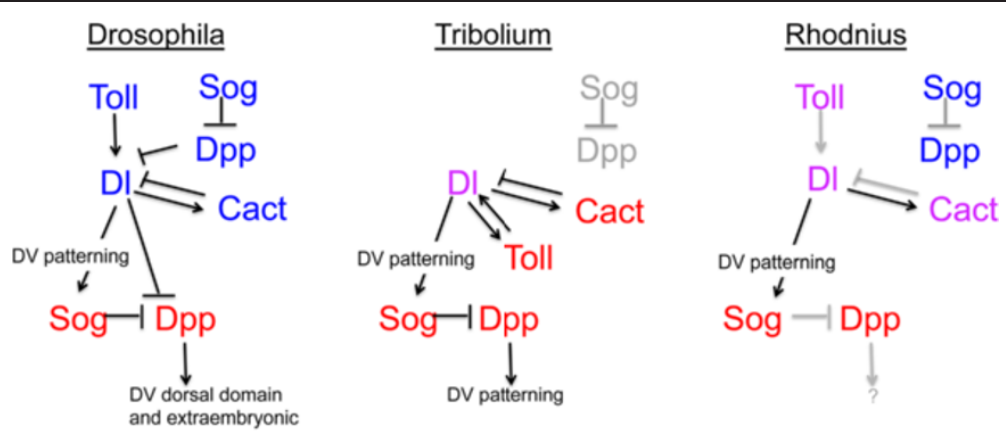

Maternal exclusively Maternal and Zygotic Zygotic

Figure 8 Model for the conserved action of Toll signals during Rhodnius dorso-ventral patterning. The hierarchical relationships between Toll and Bone Morphogenetic Protein pathways in dorso-ventral (DV) patterning have been established for Drosophila and Tribolium, either in terms of gene transcription or protein activity, and are displayed in simplified form to compare with relationships defined here for Rhodnius. Neither Tribolium nor Rhodnius Toll pathways regulate $d p p$ expression, activity required to pattern the dorsal region of the Drosophila embryo. On the other hand, a feedback loop between Toll and dl is only present in Tribolium. In the three species analyzed, $d l$ positively regulates sog expression. Arrows in black are those tested experimentally. Arrows in grey denote relations that are assumed based on conserved aspects and published evidence throughout the animal kingdom. Maternal, zygotic or maternal + zygotic expression are displayed in blue, red and pink, respectively. Maternal (blue) and zygotic (red) expression of $d p p$ and sog are not gathered as one in Drosophila and Rhodnius since their epistatic relationships to the Toll pathway differ (Drosophila), or have not been fully analyzed (Rhodnius).

amnioserosa $[48,62]$. At the beginning of gastrulation in the scuttle fly Megascelia, BMP subdivides the extraembryonic amnion and serosa as well [47]. In contrast, in Tribolium, both the Toll and BMP pathways set the entire DV axis: loss of Tc-Dpp signals causes loss of extraembryonic (dorsal-anterior) tissue and embryo expansion, while a decrease in Tc-Toll or Tc-sog results in expansion of dorsalanterior structures at the expense of embryonic tissue $[5,63,64]$.

In Rhodnius, the presence of maternal $R p$-Toll and $R p$ - $d l$ mRNAs in cleavage stage embryos, the absence of $R p-d p p$ expression at this stage, and the decrease in zygotic $R p$-sog in $R p$ - $d l$ pRNAi, suggest that maternal Toll sets the initial events in embryonic DV patterning, as shown for Drosophila (Figure 8). On the other hand, the presence of maternal $R p$-sog messages during cleavage stages suggests an early function for $R p$-sog that may differ from Sog function in either Drosophila or Tribolium. While no $R p-d p p$ expression is observed at these early stages, Rp-Sog may exert an effect on other BMPs such as Rp-Gbb, which is yet to be explored.

The lack of a central role for $R p$ - $d p p$ in setting the DV axis in Rhodnius could argue against the hypothesis that the ancestral pathway responsible for DV pattering relied on BMPs. However, we have previously shown that in Drosophila, where maternal Toll signals initiate patterned gene expression along the DV axis, maternal expression of $d p p$ [65,66] and sog [65] in follicle cells impacts DV axis formation, thus modifying the Dl gradient in the Drosophila early embryo $[65,67]$. Therefore, despite the fact that Drosophila embryos rely on Toll and $\mathrm{Dl}$ activation as the main DV patterning event, there might still be a hidden component of maternal $d p p$ in
DV patterning that corresponds to an ancestral BMP function. Interestingly, we observed that $R p$-sog and $R p-d p p$ are highly expressed during oogenesis (not shown). Thus, they may perform a patterning function in the follicular epithelium during oogenesis, or provide maternal messages and/or protein that may reflect on embryonic patterning as well. Future functional assays for BMP pathway genes should help clarify the role of the BMP pathway during Rhodnius embryogenesis, and provide insights as to the relative contribution of the BMP and Toll pathways in this hemiptera.

\section{Conclusions}

In this study, we investigated the role of the Toll pathway in Rhodnius prolixus embryonic development. We show that the Toll pathway presents maternal and zygotic components. Functional assays revealed that $R p$ - $d l$ determines early placement of the germ rudiment at the egg's posterior. In addition, embryos resulting from $R p$ - $d l$ pRNAi lack a mesodermal layer and display decreased amnion. Thus $R p-d l$ is necessary for DV patterning. While $R p$-dpp mRNAs are absent in early embryonic stages, we observe that the Toll pathway regulates zygotic expression of $R p$-sog preceding gastrulation. In conclusion, the Toll pathway is a central component in Rhodnius embryonic DV patterning.

\section{Additional files}

Additional file 1: Primer list and quantitative PCR constitutive gene analysis.

Additional file 2: Protein sequence alignment for Rp-Toll paralogs. 


\section{Additional file 3: Anti-Toll d300 specifically recognizes $R$. prolixus Toll protein.}

Additional file 4: Rp-dpp expression during early embryogenesis.

\section{Abbreviations}

AP: anterior-posterior; DV: dorso-ventral; BMP: Bone Morphogenetic Protein; bp: base pair; sog: short gastrulation; chd: chordin; dl: dorsal; dpp: decapentaplegic; GR: germ rudiment; NF: nuclear factor; PBS: phosphate-buffered saline; PCR: polymerase chain reaction; PFA: paraformaldehyde; pRNAi: parental RNA interference; Rp: Rhodnius prolixus; Tc: Tribolium castaneum.

\section{Competing interests}

The authors declare that they have no competing interests.

\section{Authors' contributions}

MB and MRF carried out the molecular studies and statistical analysis, and drafted the manuscript. MB, MRF, and HA carried out the immunoassays and morphological analysis. MB, MRF, and RNdaF performed the sequence alignment. VTS, ACR, RNdaF, and FBM carried out morphological analysis on Rp-cact. RVdA and MS identified gene sequences, and conceived and performed immune tissue analysis. HM conceived and developed conditions for animal rearing. $\mathrm{HA}$ and $\mathrm{RNdaF}$ conceived, designed, and coordinated the study and drafted the manuscript. All authors read and approved the final manuscript.

\section{Acknowledgments}

RNdaF is a Young Scientist of Rio de Janeiro Foundation for Research (FAPERJ, Brazil), supported by grants from Conselho Nacional de Desenvolvimento Científico e Tecnologico (CNPq). HA is supported by grants from FAPERJ and CNPq. The authors would like to thank Prof. Siegfried Roth and his group for sharing unpublished results, and acknowledge Prof. Roth and Dr. Attilio Pane for helpful comments on the manuscript. We are also indebted to José de S Lima and Gustavo Ali for insect care and to Dr. Pedro Oliveira for use of quantitative PCR equipment, to Carolina Batista and Nilson Santos for help with cryostat sections and Dr. Roberto Lent for use of the cryostat.

\section{Author details}

'Instituto de Ciências Biomédicas (ICB), Universidade Federal doRio de Janeiro, Av. Carlos Chagas Filho 373, Ilha do Fundão., Rio de Janeiro 21941-902 RJ, Brazil. ${ }^{2}$ Institute of Molecular Entomology, INCT-INEM, National Institutes in Science and Technology, Macaé, Brazil. ${ }^{3}$ Post-graduate Program in Morphological Sciences, Federal University of Rio de Janeiro (PCM/UFRJ), Rio de Janeiro, RJ, Brazil. ${ }^{4}$ Laboratório Integrado de Bioquímica Hatisaburo Masuda, Núcleo de Pesquisas Ecológicas de Macaé (NUPEM), Universidade Federal do Rio de Janeiro (UFRJ), Campus Macaé, Av. São José do Barreto, 764, 27937-450 Macaé, RJ, Brazil. Institute of Medical Biochemistry, Federal University of Rio de Janeiro, Rio de Janeiro, RJ, Brazil.

Received: 6 June 2014 Accepted: 11 September 2014 Published: 27 October 2014

\section{References}

1. Davis GK, Patel NH: Short, long, and beyond: molecular and embryological approaches to insect segmentation. Annu Rev Entomol 2002, 47:669-699.

2. Lynch JA, Roth S: The evolution of dorsal-ventral patterning mechanisms in insects. Genes Dev 2011, 25:107-118.

3. Moussian B, Roth S: Dorsoventral axis formation in the Drosophila embryo - shaping and transducing a morphogen gradient. Curr Biol 2005, 15:R887-R899.

4. Chen G, Handel K, Roth S: The maternal NF-kappaB/dorsal gradient of Tribolium castaneum: dynamics of early dorsoventral patterning in a short-germ beetle. Development 2000, 127:5145-5156.

5. Nunes da Fonseca R R, von Levetzow C, Kalscheuer P, Basal A, van der Zee $M$, Roth S: Self-regulatory circuits in dorsoventral axis formation of the short-germ beetle Tribolium castaneum. Dev Cell 2008, 14:605-615.

6. UV AE, Roth P, Xylourgidis N, Wickberg A, Cantera R, Samakovlis C: Members only encodes a Drosophila nucleoporin required for rel protein import and immune response activation. Genes Dev 2000, 14:1945-1957.
7. Van der Zee M, da Fonseca RN, Roth S: TGFbeta signaling in Tribolium: vertebrate-like components in a beetle. Dev Genes Evol 2008, 218:203-213.

8. Akiyama-Oda Y, Oda H: Axis specification in the spider embryo: dpp is required for radial-to-axial symmetry transformation and sog for ventral patterning. Development 2006, 133:2347-2357.

9. Buchta T, Ozuak O, Stappert D, Roth S, Lynch JA: Patterning the dorsalventral axis of the wasp Nasonia vitripennis. Dev Biol 2013, 381:189-202.

10. Wilson MJ, Kenny NJ, Dearden PK: Components of the dorsal-ventral pathway also contribute to anterior-posterior patterning in honeybee embryos (Apis mellifera). EvoDevo 2014, 5:11.

11. Özüak O, Buchta T, Roth S, Lynch JA: Embryonic dorsoventral polarity in the wasp Nasonia relies primarily on a BMP gradient formed without input from Toll signaling. Curr Biol 2014, in press.

12. WHO: Chagas Disease (American trypanosomiasis). In Fact Sheet, Volume $\mathrm{N}^{\circ} 340 ; 2013$.

13. Medeiros MN, Logullo R, Ramos IB, Sorgine MH, Paiva-Silva GO, Mesquita RD, Machado EA, Coutinho MA, Masuda H, Capurro ML, Ribeiro JM, Cardoso Braz GR, Oliveira PL: Transcriptome and gene expression profile of ovarian follicle tissue of the triatomine bug Rhodnius prolixus. Insect Biochem Mol Biol 2011, 41:823-831.

14. Ribeiro JM, Genta FA, Sorgine MH, Logullo R, Mesquita RD, Paiva-Silva GO, Majerowicz D, Medeiros M, Koerich L, Terra WR, Ferreira C, Pimentel AC, Bisch PM, Leite DC, Diniz JL, da S G V Junior JL, Da Silva ML, Araujo RN, Gandara AC, Brosson S, Salmon D, Bousbata S, González-Caballero N, Silber AM, Alves-Bezerra M, Gondim KC, Silva-Neto MA, Atella GC, Araujo H, Dias FA, et al: An insight into the transcriptome of the digestive tract of the bloodsucking Bug, rhodnius prolixus. PLoS Negl Trop Dis 2014, 8:e2594.

15. Ribeiro JM, Andersen J, Silva-Neto MA, Pham VM, Garfield MK, Valenzuela JG: Exploring the sialome of the blood-sucking bug Rhodnius prolixus. Insect Biochem Mol Biol 2004, 34:61-79.

16. Huebner $\mathrm{E}$, Anderson E: A cytological study of the ovary of Rhodnius prolixus. I. The ontogeny of the follicular epithelium. J Morphol 1972, 136:459-493.

17. Wigglesworth VB: The fate of haemoglobin in rhodnius prolixus (hemiptera) and other blood-sucking arthropods. Proc R Soc Lond B 1943, 131:313-339.

18. Kelly GM, Huebner E: Experimental analysis of Rhodnius prolixus (Insecta, Hemiptera) embryogenesis. Prog Clin Biol Res 1986, 217A:423-426.

19. Kelly GM, Huebner E: Embryonic development of the hemipteran insect rhodnius prolixus. J Morphol 1989, 199:175-196.

20. Mellanby $\mathrm{H}$ : The early embryonic development of rhodnius prolixus (hemiptera, heteroptera). Quart J Micr Sci 1935, 78:71-91.

21. Mellanby H: The latter embryology of Rhodnius prolixus. Quart J Micr Sci 1935, 313:1-40.

22. Araujo RN, Santos A, Pinto FS, Gontijo NF, Lehane MJ, Pereira MH: RNA interference of the salivary gland nitrophorin 2 in the triatomine bug Rhodnius prolixus (Hemiptera: Reduviidae) by dsRNA ingestion or injection. Insect Biochem Mol Biol 2006, 36:683-693.

23. Lavore A, Esponda-Behrens N, Pagola L, Rivera-Pomar R: The gap gene Kruppel of Rhodnius prolixus is required for segmentation and for repression of the homeotic gene sex comb-reduced. Dev Biol 2014, 387:121-129.

24. Lavore A, Pagola L, Esponda-Behrens N, Rivera-Pomar R: The gap gene giant of Rhodnius prolixus is maternally expressed and required for proper head and abdomen formation. Dev Biol 2012, 361:147-155.

25. Paim RM, Araujo RN, Lehane MJ, Gontijo NF, Pereira MH: Long-term effects and parental RNAi in the blood feeder Rhodnius prolixus (Hemiptera; Reduviidae). Insect Biochem Mol Biol 2013, 43:1015-1020.

26. Souza-Ferreira PS, Mansur JF, Berni M, Moreira MF, Dos Santos RE, Araujo HM, de Souza W, Ramos IB, Masuda H: Chitin deposition on the embryonic cuticle of Rhodnius prolixus: the reduction of CHS transcripts by CHS-dsRNA injection in females affects chitin deposition and eclosion of the first instar nymph. Insect Biochem Mol Biol 2014, 51:101-108.

27. Souza-Ferreira PS, Moreira MF, Atella GC, Oliveira-Carvalho AL, Eizemberg R, Majerowicz D, Melo AC, Zingali RB, Masuda H: Molecular characterization of Rhodnius prolixus embryonic cuticle. Insect Biochem Mol Biol 2014, 51:89-100.

28. Tamura K, Stecher G, Peterson D, Filipski A, Kumar S: MEGA6: molecular evolutionary genetics analysis version 6.0. Mol Biol Evol 2013, 30:2725-2729.

29. Livak KJ, Schmittgen TD: Analysis of relative gene expression data using real-time quantitative PCR and the 2(-Delta Delta $C(T)$ ) Method. Methods 2001, 25:402-408. 
30. Pfaffl MW: A new mathematical model for relative quantification in realtime RT-PCR. Nucleic Acids Res 2001, 29:e45.

31. Majerowicz D, Alves-Bezerra M, Logullo R, Fonseca-de-Souza AL, MeyerFernandes JR, Braz GR, Gondim KC: Looking for reference genes for realtime quantitative PCR experiments in Rhodnius prolixus (Hemiptera: Reduviidae). Insect Mol Biol 2011, 20:713-722.

32. Heming BS, Huebner E: Development of the germ cells and reproductive primordia in male and female embryos of Rhodnius prolixus Stil (Hemiptera: Reduviidae). Can J Zool 1994, 72:1100-1120.

33. Panfilio KA: Extraembryonic development in insects and the acrobatics of blastokinesis. Dev Biol 2008, 313:471-491.

34. van der Zee M, Berns N, Roth S: Distinct functions of the Tribolium zerknullt genes in serosa specification and dorsal closure. Curr Biol 2005, 15:624-636

35. Handel K, Grunfelder CG, Roth S, Sander K: Tribolium embryogenesis: a SEM study of cell shapes and movements from blastoderm to serosal closure. Dev Genes Evol 2000, 210:167-179.

36. Panfilio KA, Liu PZ, Akam M, Kaufman TC: Oncopeltus fasciatus zen is essential for serosal tissue function in katatrepsis. Dev Biol 2006, 292:226-243.

37. Panfilio KA, Roth S: Epithelial reorganization events during late extraembryonic development in a hemimetabolous insect. Dev Biol 2010, 340:100-115.

38. Ursic-Bedoya R, Buchhop J, Lowenberger C: Cloning and characterization of Dorsal homologues in the hemipteran Rhodnius prolixus. Insect $\mathrm{Mol}$ Biol 2009, 18:681-689.

39. Walter-Nuno AB, Oliveira MP, Oliveira MF, Goncalves RL, Ramos IB, Koerich LB, Oliveira PL, Paiva-Silva GO: Silencing of maternal heme-binding protein causes embryonic mitochondrial dysfunction and impairs embryogenesis in the blood sucking insect Rhodnius prolixus. J Biol Chem 2013, 288:29323-29332.

40. Ooi JY, Yagi Y, Hu X, Ip YT: The Drosophila Toll-9 activates a constitutive antimicrobial defense. EMBO Rep 2002, 3:82-87.

41. Tauszig S, Jouanguy E, Hoffmann JA, Imler JL: Toll-related receptors and the control of antimicrobial peptide expression in Drosophila. Proc Nat Acad Sci U S A 2000, 97:10520-10525.

42. Yagi Y, Nishida Y, Ip YT: Functional analysis of Toll-related genes in Drosophila. Dev Growth Differ 2010, 52:771-783.

43. Christophides GK, Zdobnov E, Barillas-Mury C, Birney E, Blandin S, Blass C, Brey PT, Collins FH, Danielli A, Dimopoulos G, Hetru C, Hoa NT, Hoffmann JA, Kanzok SM, Letunic I, Levashina EA, Loukeris TG, Lycett G, Meister S, Michel K, Moita LF, Müller HM, Osta MA, Paskewitz SM, Reichhart JM, Rzhetsky A, Troxler L, Vernick KD, Vlachou D, Volz J, et al: Immunity-related genes and gene families in Anopheles gambiae. Science 2002, 298:159-165.

44. Luna C, Wang X, Huang Y, Zhang J, Zheng L: Characterization of four Toll related genes during development and immune responses in Anopheles gambiae. Insect Biochem Mol Biol 2002, 32:1171-1179.

45. Zou Z, Evans JD, Lu Z, Zhao P, Williams M, Sumathipala N, Hetru C, Hultmark D, Jiang $\mathrm{H}$ : Comparative genomic analysis of the Tribolium immune system. Genome Biol 2007, 8:R177.

46. Goltsev Y, Fuse N, Frasch M, Zinzen RP, Lanzaro G, Levine M: Evolution of the dorsal-ventral patterning network in the mosquito, Anopheles gambiae. Development 2007, 134:2415-2424.

47. Rafiqi AM, Park CH, Kwan CW, Lemke S, Schmidt-Ott U: BMP-dependent serosa and amnion specification in the scuttle fly Megaselia abdita. Development 2012, 139:3373-3382.

48. Wharton KA, Ray RP, Gelbart WM: An activity gradient of decapentaplegic is necessary for the specification of dorsal pattern elements in the Drosophila embryo. Development 1993, 117:807-822.

49. Lynch JA, Peel AD, Drechsler A, Averof M, Roth S: EGF signaling and the origin of axial polarity among the insects. Curr Biol 2010, 20:1042-1047.

50. Anderson KV, Jurgens G, Nusslein-Volhard C: Establishment of dorsalventral polarity in the Drosophila embryo: genetic studies on the role of the Toll gene product. Cell 1985, 42:779-789.

51. Miya K, Kobayashi K: The embryonic development of Atrachya menetres. Falderman (Coleoptera, Chrisomelidae). II Analyses of early development by ligation and low temperature treatment. Fac Agric Iwate Univ 1974, 12:39-55.

52. Weisbrod A, Cohen M, Chipman AD: Evolution of the insect terminal patterning system - insights from the milkweed bug, Oncopeltus fasciatus. Dev Biol 2013, 380:125-131.

53. Price AL, Modrell MS, Hannibal RL, Patel NH: Mesoderm and ectoderm lineages in the crustacean Parhyale hawaiensis display intra-germ layer compensation. Dev Biol 2010, 341:256-266.

54. Santos VT, Ribeiro L, Fraga A, de Barros CM, Campos E, Moraes J, Fontenele MR, Araujo HM, Feitosa NM, Logullo C, da Fonseca RN: The embryogenesis of the tick Rhipicephalus (Boophilus) microplus: the establishment of a new chelicerate model system. Genesis 2013, 51:803-818.

55. Gilmore TD, Wolenski FS: NF-kappaB: where did it come from and why? Immunol Rev 2012, 246:14-35.

56. Lynch JA, El-Sherif E, Brown SJ: Comparisons of the embryonic development of Drosophila, Nasonia, and Tribolium. Wiley Interdiscip Rev Dev Biol 2012, 1:16-39.

57. De Robertis EM: Evo-devo: variations on ancestral themes. Cell 2008, 132:185-195.

58. Cande J, Goltsev Y, Levine MS: Conservation of enhancer location in divergent insects. Proc Natl Acad Sci U S A 2009, 106:14414-14419.

59. Biemar F, Nix DA, Piel J, Peterson B, Ronshaugen M, Sementchenko V, Bell I, Manak JR, Levine MS: Comprehensive identification of Drosophila dorsalventral patterning genes using a whole-genome tiling array. Proc Nat Acad Sci U S A 2006, 103:12763-12768

60. Papatsenko $D$, Levine $M$ : Quantitative analysis of binding motifs mediating diverse spatial readouts of the Dorsal gradient in the Drosophila embryo. Proc Natl Acad Sci U S A 2005, 102:4966-4971.

61. Stathopoulos A, Levine M: Dorsal gradient networks in the Drosophila embryo. Dev Biol 2002, 246:57-67.

62. Decotto E, Ferguson EL: A positive role for Short gastrulation in modulating BMP signaling during dorsoventral patterning in the Drosophila embryo. Development 2001, 128:3831-3841.

63. Nunes da Fonseca R, van der Zee M, Roth S: Evolution of extracellular Dpp modulators in insects: the roles of tolloid and twisted-gastrulation in dorsoventral patterning of the Tribolium embryo. Dev Biol 2010, 345:80-93.

64. van der Zee M, Stockhammer O, von Levetzow C, Nunes da Fonseca R, Roth S: Sog/Chordin is required for ventral-to-dorsal Dpp/BMP transport and head formation in a short germ insect. Proc Natl Acad Sci U S A 2006, 103:16307-16312

65. Araujo H, Bier E: Sog and dpp exert opposing maternal functions to modify toll signaling and pattern the dorsoventral axis of the Drosophila embryo. Development 2000, 127:3631-3644.

66. Twombly V, Blackman RK, Jin H, Graff JM, Padgett RW, Gelbart WM: The TGF-beta signaling pathway is essential for Drosophila oogenesis. Development 1996, 122:1555-1565.

67. Carneiro K, Fontenele M, Negreiros E, Lopes E, Bier E, Araujo H: Graded maternal short gastrulation protein contributes to embryonic dorsalventral patterning by delayed induction. Dev Biol 2006, 296:203-218.

doi:10.1186/2041-9139-5-38

Cite this article as: Berni et al.: Toll signals regulate dorsal-ventral patterning and anterior-posterior placement of the embryo in the hemipteran Rhodnius prolixus. EvoDevo 2014 5:38.

\section{Submit your next manuscript to BioMed Central and take full advantage of:}

- Convenient online submission

- Thorough peer review

- No space constraints or color figure charges

- Immediate publication on acceptance

- Inclusion in PubMed, CAS, Scopus and Google Scholar

- Research which is freely available for redistribution 